\title{
Avaliação formativa por meio de alunos tutores: efeitos no desempenho cognitivo e na satisfação do aluno
}

\author{
ELAINE APARECIDA DA SILVA \\ JOSÉ FLORÊNCIO RODRIGUES JUNIOR**
}

\section{RESUMO}

Objetiva-se, neste estudo, analisar os efeitos da avaliaçáo formativa, com suporte de alunos tutores, na aprendizagem de Matemática na primeira série do ensino médio. Distingue-se, nesse processo, o domínio cognitivo, considerando-se as categorias taxonômicas Conhecimento, Compreensão e Aplicação e a aprendizagem afetiva. Foi utilizada metodologia experimental, por meio de delineamento quase-experimental, com duas turmas: uma experimental e outra controle. A instrumentação empregada consistiu em: a) pré e pós testes para aferir a aprendizagem cognitiva; e b) questionário com perguntas abertas para verificar o nível de satisfação dos dois grupos em relação ao procedimento de avaliação utilizado. Pelos dados coletados, concluiu-se, mediante análise de covariância, não existirem diferenças estatisticamente significativas na aprendizagem cognitiva, quer considerada como um todo, quer considerada nas categorias taxonômicas, distintamente. Quanto à satisfação dos alunos integrantes da pesquisa, porém, houve diferença estatisticamente significativa que favorece o grupo experimental. Pode-se

* Professora de Matemática do ensino fundamental e médio do Centro Educacional da Católica de Brasília (elainesweb2004@yahoo.com.br).

${ }^{* *}$ Professor do Mestrado em Educação da Universidade Católica de Brasília (jfloren@apis.com.br). 
afirmar, ainda, com base nas observaçóes da pesquisadora e nos registros feitos pelos alunos, que a prática da avaliação formativa, com suporte de alunos tutores, beneficia a aprendizagem, pois torna o ambiente em sala de aula mais agradável e dinâmico.

Palavras-chave: avaliação da aprendizagem, ensino médio, ensino de matemática, taxonomia educacional.

\section{RESUMEN}

El objetivo de este estudio es analizar los efectos de la evaluación formativa, con el soporte de alumnos tutores, en el aprendizaje de Matemáticas en el primer ańo de la enseñanza media. En este proceso se diferencian, el dominio cognoscitivo, considerando las categorías taxonómicas Conocimiento, Comprensión y Aplicación y el aprendizaje afectivo. Se utilizó una metodología experimental por medio de un delineamiento cuasi-experimental, con dos grupos: uno experimental y otro de control. Los instrumentos empleados consistieron en: a) pre y post pruebas para medir el aprendizaje cognoscitivo; y b) cuestionarios con preguntas abiertas para verificar el nivel de satisfacción de los dos grupos en relación al procedimiento de evaluación utilizado. Por los datos relevados se concluyó, mediante el análisis de covarianza, que no existían diferencias estadísticamente significativas en el aprendizaje cognoscitivo, ya sea considerándolo como un todo o en cada una de las categorías taxonómicas. En cuanto al nivel de satisfacción de los alumnos integrantes de la experiencia, hubo sin embargo, una diferencia estadísticamente significativa que favorece al grupo experimental. A partir de las observaciones de la investigadora y de los registros realizados por los alumnos, se concluye también que la práctica de la evaluación formativa, realizada con el apoyo de alumnos tutores, beneficia el aprendizaje ya que torna el ambiente del aula más agradable y dinámico.

Palabras clave: evaluación del aprendizaje, enseñanza media, enseñanza de matemáticas, taxonomía educativa.

\section{ABSTRACT}

The present study analyzes the effects of an evaluation methodology designed to assist $10^{\text {th }}$ grade students in overcoming difficulties in learning Mathematics. The study has three specific objectives: (a) to compare the performance, in cognitive learning, of a group assessed by means of a formative procedure, supported by peer tutors, with a control group, lacking this procedure; (b) to examine the performance of the experimental and the control groups as to their cognitive learning with reference to the taxonomic categories Knowledge, Comprehension, and Application; and (c) to ascertain the level of satisfaction of both groups concerning the evaluation procedure adopted in Mathematics, first year, middle school. The approach employed in the study was experimental, by way of a quasi-experimental design utilizing an experimental and a control group, both pre- and pos-tested with the purpose of assessing the achievement of both groups. In addition to the quantitative approach, a qualitative one was used by means of an open-ended questionnaire, intended to examine the level of satisfaction of both groups regarding the evaluation procedure adopted, the questionnaire being complemented with observations by the researcher and records of students from the experimental group during the experiment. The data collected showed no overall statistical 
differences between the two groups; the same occurred when the data was analyzed with a focus on the categories Knowledge, Comprehension and Application as set out in the Taxonomy of Educational Objectives. However, the level of satisfaction of the experimental group about the evaluation procedure adopted was significantly higher than the control group's. Besides, it was shown, on the basis of records by the researcher and by the students, that formative evaluation coupled with peer-tutoring promotes learning, as it turns the classroom into a more pleasant and dynamic learning environment.

Keywords: learning assessment, high school, Mathematics teaching, educational taxonomy. 


\section{INTRODUÇÃO}

A avaliaçáo tem despertado o interesse dos vários segmentos envolvidos no processo educacional: gestores, professores, alunos, entre outros. Tem sido também alvo de numerosos estudos e críticas, cujos resultados deixam sem resposta conclusiva questóes tanto de ordem teórica como prática.

Atualmente, a avaliação do processo educacional, na educação básica, emprega desde testes em larga escala, como, por exemplo, o Sistema Nacional de Avaliação da Educação Básica (Saeb) e o Exame Nacional do Ensino Médio (Enem), até trabalhos, provas e testes, no ambiente de sala de aula, para detectar problemas e aferir desempenhos com vistas à melhoria do processo ensino-aprendizagem.

Os resultados desses testes (por exemplo, o Saeb) demonstram que a situaçáo da aprendizagem em Matemática vai mal. É o que conclui o estudo "Qualidade da educação: uma nova leitura do desempenho dos estudantes da quarta série do ensino fundamental" (Brasil, 2004). O referido estudo inclui em sua análise resultados do Saeb 2001 obtidos de testes administrados à oitava serie do ensino fundamental e à terceira do ensino médio. De acordo com esses resultados, cerca de $50 \%$ dos alunos da quarta série do ensino fundamental encontram-se nos níveis crítico ou muito crítico. Esse índice sobe para cerca de $60 \%$ na oitava série e atinge, aproximadamente, $67 \%$ dos alunos da terceira série do ensino médio. Esse resultado praticamente se manteve o mesmo no Saeb 2003.

\section{AVALIAÇÃO EDUCACIONAL COM FOCO NA AVALIAÇÃO FORMATIVA}

O estágio de desenvolvimento da avaliaçáo educacional, tal como se encontra hoje, foi iniciado com o trabalho de Ralph Tyler na década de 1930. O autor empenhou todo o seu esforço para tornar a avaliaçáo um meio de assegurar a eficácia da instrução (Cahen; Anderson, 1977). Antes desse período, houve um desenvolvimento incipiente dos testes padronizados de escolaridade os quais se centravam apenas nas habilidades dos indivíduos.

A gênese da ideia de avaliaçâo formativa surgiu com o "Modelo de Aprendizagem Escolar", de Carroll (1963), no qual os estudantes eram distribuídos em turmas, de acordo com sua aptidáo. A esses estudantes, era dada a mesma instruçáo com base nas características individuais de cada aluno e da turma. Nesse modelo, a quantidade de conhecimento adquirido, desde o início até o final da instrução, era relativamente alta: acima de 70\% (Carroll, 1963 apud Bloom, 1976).

Bloom (1976), em seu livro Human characteristics and school learning, elaborou e expandiu o modelo de Carroll, formalizando o que veio a se chamar aprendizagem 
para o domínio (mastery learning). A formulação de Bloom estabelecia que a maioria dos estudantes, independentemente de sua aptidão, poderia atingir alto nível de domínio de conhecimento, desde que fossem ajudados em suas dificuldades de aprendizagem, tivessem tempo suficiente para adquirir tal domínio e houvesse critérios claros para decidir sobre o atingimento ou não desse domínio. Baseado nisso, Bloom desenvolveu a teoria da aprendizagem escolar, na qual, para avaliar o conhecimento adquirido pelos estudantes, seriam utilizados os testes formativos para dar feedback aos estudantes e ao professor. Bloom ainda cita Husén e Crosswhite, os quais se referem a estudos sobre afetividade em Matemática. Os estudos desses pesquisadores comprovaram existir relação entre afetividade e aquisição de conhecimentos. Explicitando: os estudantes que apresentavam afetividade positiva em relação a Matemática obtiveram médias mais elevadas em seus testes de conhecimento.

A formulação da avaliação formativa como recurso na avaliação educacional é creditada a Scriven (Lewy, 1990). Confrontando a avaliação formativa com a somativa, praticada maciçamente em contextos escolares, Scriven prescreve a prática da avaliação formativa no decorrer da instrução e com finalidade informativa em vez de atribuição de nota. Alerta também sobre a prática equivocada de somarem resultados de diferentes avaliaçóes formativas; essa prática, esclarece, constitui uma deformação da avaliação formativa, transformando-a em somativa (Scriven, 1967).

Outros estudiosos em avaliação educacional explicitam a avaliação formativa de modo semelhante ao de Scriven. Por exemplo, Perrenoud (1999) afirma que a avaliaçáo formativa consiste em um modo de regular a aprendizagem, individualizando-a. Assim, no entender desse especialista, a avaliação fornece ao aluno um diagnóstico individualizado para que este identifique seu nível de domínio do conteúdo, assim como suas deficiências, podendo, então, suprir e corrigir estas últimas. Dessa maneira, a avaliação formativa diferencia-se da tradicional por situar-se ao longo da instruçáo, possibilitando aos professores ajustar o ensino às necessidades de seus alunos.

Harlen e James, citados por Villas Boas (2004), apontam as seguintes características da avaliação formativa: (a) é conduzida pelo professor; (b) destina-se a promover a aprendizagem; (c) leva em conta o progresso individual, o esforço nele colocado e outros aspectos não especificados no currículo, isto é, não é inteiramente baseada em critérios; (d) nela, capacidades e ideias, que na avaliação somativa poderiam ser classificadas como erros, fornecem informaçóes diagnósticas; e (e) os alunos exercem papel central, devendo atuar ativamente em sua própria aprendizagem, ou seja, eles progredirão se compreenderem suas possibilidades e fragilidades e se 
souberem como se relacionar com elas. A avaliação formativa é associada, também, à avaliação informal, realizada por meio da interaçáo do aluno com os professores, colegas e demais profissionais da educação (Villas Boas, 2004).

Presentemente, a avaliação formativa conta com expressivos defensores, como os educadores Allal, Cardinet e Perrenoud (1986), Perrenoud (1988) e Hoffmann (2005b). Os primeiros propóem uma sequência de três etapas fundamentais nesse tipo de avaliação: o recolhimento de informaçóes relativas aos progressos e às dificuldades de aprendizagem apresentados pelos alunos; a interpretação dessas informaçóes com referência a critérios; e a adaptação das atividades de ensino e de aprendizagem de acordo com a interpretação das informaçóes recolhidas.

Perrenoud (1988) enumera as condições necessárias para que a avaliação praticada nas salas de aula se torne verdadeiramente formativa. Entre as mais importantes, destacam-se quatro: (a) na avaliação formativa há a necessidade de uma intervenção, uma remediaçáo; (b) uma pedagogia nova implica mudanças profundas nos currículos e na didática; (c) deve-se dar autonomia aos professores, ter confiança na sua intuição e na capacidade que têm de improvisação. A avaliação formativa não é uma prática espontânea, logo é necessário treinar os professores, difundir modelos, propor instrumentos e maneiras de fazê-la; (d) a melhor maneira de implantar um modelo de avaliação formativa, que se adapte à realidade na qual vivem, seria convidar os professores e gestores a criá-lo, utilizando sua imaginação e competência, com a colaboração de especialistas em sistemas de avaliação formativa ou de investigadores na instrução. É inútil esperar que professores mal treinados, mal pagos, submetidos a um conjunto de diretrizes orientadoras burocráticas, sintam desejo e coragem de desenvolver a avaliação formativa. Nesses casos, com a simples determinação superior, não se conseguirá implantar a avaliação formativa eficaz.

Pesquisas realizadas no Brasil, que focalizam a prática da avaliação formativa, têm demonstrado resultados favoráveis. Elas têm sido experimentais, do ponto de vista de delineamento, tendo um grupo experimental, ao qual se administra instrução apoiada na avaliação formativa, e um grupo controle, que recebe instrução sem o emprego desse recurso avaliativo. Quatro pesquisas são revisadas sumariamente com o fito de apresentar evidência em favor dessa prática.

Almeida (1976) administrou instrução por meio de módulos de ensino sobre conteúdos de Matemática, Física e Língua Portuguesa a alunos de primeira série do ensino médio, aplicando a avaliação formativa a esse grupo experimental. Em um teste somativo final, nesse grupo, obteve resultados superiores aos do grupo controle. Resultados semelhantes foram observados por Klausner (1977) com alunas de um 
curso de estudos adicionais na área de Estudos Sociais de uma instituição de ensino de segundo grau do Espírito Santo. Correlaçóes entre resultados de avaliaçóes formativas e somativas foram significativas em metade das comparaçóes. Retomando o delineamento experimental, Dutra (1977) aplicou a avaliação formativa em uma turma experimental de um curso de Pedagogia, tendo um grupo controle paralelamente. O desempenho do grupo experimental foi superior ao do grupo controle em um teste somativo. Finalmente, Silva (2002) replicou o estudo de Dutra, administrando avaliaçáo formativa com tutoria a uma turma experimental de Cálculo de uma universidade privada do Centro-Oeste, que apresentou resultados superiores quando confrontados com os dados obtidos por uma turma controle.

\section{TUTORIA POR ALUNOS}

A tutoria por alunos é um procedimento de ensino centralizado no professor, o qual, no comando da instrução, utiliza como auxiliares alguns alunos que ajudam outros que apresentam dificuldade em aprender. Sáo geralmente da mesma turma, no entanto podem ser de séries mais avançadas. Atuam durante o período de aula, ou, eventualmente, em outros períodos, sob a coordenaçáo do docente.

Estudos centralizados nessa forma de instrução mostram resultados favoráveis, tanto nos aspectos cognitivos quanto nos afetivos. Bloom (1976) refere-se à tutoria ideal, a qual consiste no ensinamento de apenas um aluno pelo professor. Ressalta, ainda, que o aumento no número de alunos pode influenciar negativamente na instrução.

Em grande parte dos estudos sobre tutoria, utilizam-se alunos de séries mais adiantadas como tutores. Em alguns deles, compara-se o efeito da tutoria por alunos mais adiantados com a tutoria por tutores professores. Os resultados favorecem a tutoria por alunos, o que ocorre tanto no ensino fundamental quanto no ensino superior (De Volder; De Grave; Gijselaers, 1985).

Robinson e seus colaboradores (2005) concluem, com base em seu estudo, que a tutoria tem fundamental importância na melhora da aquisição de conhecimentos em Matemática para estudantes americanos de origem africana, bem como para estudantes americanos brancos. O nível de aquisição nesses programas é variado, podendo alcançar resultados bastante elevados ou não. Nota-se adicionalmente, que programas de tutoria induzem à formação de resultados extremamente positivos relacionados às atitudes e ao comportamento socioemocional dos alunos. Além disso, tutores e tutorados tendem a uma trajetória acadêmica de sucesso em Matemática e em outros campos do conhecimento. 
No presente estudo, utilizou-se a tutoria de alunos como recurso para remediar deficiências de aprendizagem detectadas nas avaliaçóes formativas. O procedimento, réplica ao estudo de Silva com alunos de Cálculo do Ensino Superior, foi realizado na própria sala de aula durante o horário de instrução da disciplina. Outros dados sobre o procedimento são fornecidos na seção a seguir.

\section{METODOLOGIA}

Trata-se de uma pesquisa experimental, conduzida com base em modelo denominado quase-experimental. Consoante esse modelo, compara-se o rendimento e a satisfação de dois grupos de alunos: um submetido ao procedimento da avaliação formativa associado à tutoria por alunos (grupo experimental - GE) e o outro sem os referidos procedimentos (grupo controle - GC). Trata-se, na realidade, de uma replicação ao trabalho de Silva (2002), o qual, por sua vez, replicou a pesquisa de Dutra (1977).

O trabalho restringiu-se ao âmbito do ensino médio (primeira série) e o rendimento dos alunos foi aferido com base nas categorias da Taxonomia de Bloom e seus colaboradores (1972) - Conhecimento, Compreensão e Aplicação. Além da satisfação dos alunos com referência ao procedimento de avaliação utilizado, foi observado também o comportamento dos alunos, em sala, nos trabalhos em grupo e daqueles que desempenharam a função de tutores para a suplementação da instruçáo.

O desempenho cognitivo, conforme assinalado anteriormente, foi aferido com base na Taxonomia de Objetivos Educacionais. Silva (2002) tomou como referência as categorias cognitivas Conhecimento, Compreensão e Aplicação; o mesmo foi feito no presente estudo. Essas categorias de aprendizagem cognitiva refletem: a de Conhecimento, processos de memória; a de Compreensão, processos de transformação da informação; e a de Aplicação, processos de translado da informação para situaçóes problemáticas particulares (Rodrigues Junior, 1994).

Os dois grupos GE e GC foram submetidos a um teste diagnóstico (pré-teste) para avaliar seu desempenho em relação a determinados conteúdos a serem transmitidos no terceiro e quarto bimestres letivos (semelhança de triângulos e progressóes aritméticas). Depois desse teste, os dois grupos assistiram a quatro aulas semanais com a mesma professora, utilizando o mesmo livro-texto, fazendo os mesmos exercícios sobre os referidos assuntos, durante, aproximadamente, dois meses. Tais aulas foram ministradas pela autora da pesquisa, a fim de controlar o efeito de diferentes estilos de instruçáo. Nesse período, o GE recebeu, a cada três aulas, um teste para verificar o alcance dos objetivos propostos nessas aulas. Ao mesmo tempo, foi 
oferecido suporte na instrução, por meio de alunos tutores, no início e ao final do período de aulas, para esse grupo (GE).

Durante as aulas, para resolver os exercícios, os alunos dividiam-se em sete grupos cada qual com aproximadamente sete alunos, sendo um deles o tutor. No período de tutoria, antes, durante e após a aula, a professora fez registros de observação dos comportamentos e impressôes sobre o método de avaliação utilizado pelo GE. Registrou, igualmente, impressóes de alunos, tutores ou não, em relação ao procedimento utilizado. Após esse período, os grupos foram submetidos ao pós-teste para aferir o desempenho. O teste da hipótese nula do estudo foi efetuado por meio da análise de covariância, com os escores do pré-teste como covariável, tendo como principal finalidade o controle estatístico da variabilidade. Aos dois grupos foi aplicado, também, um questionário para verificar a satisfação dos alunos em relação aos procedimentos avaliativos empregados.

\section{APRESENTAÇÃO E DISCUSSÃO DOS RESULTADOS}

Nesta última seção, sumariam-se os resultados dos testes das hipóteses, comentando-os à luz da literatura compulsada. Primeiramente, são apresentados os resultados relativos ao desempenho cognitivo, depois os resultados sobre a satisfaçáo dos alunos participantes do experimento.

\section{Resultados quanto ao desempenho cognitivo dos grupos}

Neste trabalho, fez-se a comparação de dois grupos submetidos a dois tipos de avaliação distintos. No grupo experimental, foram utilizadas as avaliaçóes formativa e somativa, e no grupo controle, apenas a avaliação somativa. Desejou-se saber se o rendimento cognitivo do primeiro grupo foi superior ao do segundo. Tal rendimento foi analisado globalmente e, também, por categorias da Taxonomia de Objetivos Educacionais - Conhecimento, Compreensão e Aplicação (Bloom e colaboradores, 1972) - e, para compará-lo, optou-se pela análise de covariância. O pré-teste e o pós-teste constituíram-se do mesmo instrumento.

A hipótese levantada, em relação ao desempenho dos alunos, foi a seguinte: inexiste diferença significativa no desempenho cognitivo e no desempenho global de alunos avaliados com base apenas na avaliação somativa e no desempenho de alunos que, além da avaliação somativa, realizaram avaliação formativa.

Concluiu-se, por meio dos dados, que não houve diferença estatisticamente significativa no desempenho cognitivo dos alunos nessas categorias, nem no de- 
sempenho cognitivo global, dado que os valores de $\mathrm{p}$ encontrados foram superiores a 0,05. Especificando: o valor de p para a categoria Conhecimento foi 0,462, para a categoria Compreensão, 0,453, para a categoria Aplicaçáo, 0,131 e para o teste global, 0,353. Este resultado coincide com os de dois estudos anteriores, feitos também no âmbito do ensino médio. Os estudos de Silva (1979) e Paredes (1984), aludidos na revisão de literatura, mostraram resultados equivalentes, ou seja, não houve diferença significativa no desempenho cognitivo dos alunos submetidos à avaliação formativa.

Por outro lado, esse resultado difere do encontrado por Silva (2002), o qual assinalou diferenças estatisticamente significativas, favorecendo o grupo experimental. Ressalta-se, no entanto, que este último estudo foi feito no ensino superior. Outros estudos citados por Black e Wiliam (1998), também assinalaram ganhos estatisticamente significativos, favorecendo o grupo experimental em pesquisas feitas, incluindo a disciplina Matemática. Esses estudos demonstraram que alunos submetidos a testes frequentes, aos quais era dado feedback constante, foram os que mais sobressaíram.

Os alunos do grupo experimental registraram suas impressóes a respeito do trabalho e classificaram como excelente o uso de testes frequentes. Eles argumentaram que, com esses testes, ficava mais fácil saber o que estavam aprendendo, ou náo, e o que ainda precisavam estudar. Os alunos que atuavam como tutores encontraram nos testes uma maneira de verificar até que ponto estavam preparados para prosseguir nos próximos assuntos e ajudar seus colegas, pois quando se deparavam com alguma questão que não conseguiam responder procuravam o professor para sanar suas dúvidas.

Sugeriram, ainda, que os testes abordassem uma quantidade maior de conteúdos, com questóes mais complexas, seguindo a linha adotada na elaboração das provas do Programa de Avaliação Seriada (PAS) - programa alternativo de acesso ao ensino superior, adotado pela Universidade de Brasília. Esse fato comprova quanto ainda é predominante e valorizada, entre os alunos e suas famílias, a função somativa da avaliação, especialmente a cultura do vestibular.

Ainda foram colhidas outras informações, por meio do questionário e de entrevistas, as quais clarificam aspectos da prática da avaliação formativa, bem como da tutoria. Alguns alunos opinaram que com os testes tinham a vantagem rever conteúdos anteriores, porém que se perdia muito tempo da aula, em vez de avançar na cobertura de novos conteúdos. Outros ainda assinalaram que os grupos deveriam se reunir mais vezes, pois assim teriam todas as dúvidas sanadas. Um dos 
alunos que atuou como tutor e teve um desempenho elevado em todos os testes, incluindo o pré-teste e o pós-teste, disse que as questóes estavam muito fáceis e que resolveu todas sem dificuldade. Esse fato contrasta com o de outros dois alunos que se mostraram completamente desinteressados durante o trabalho, desde a resolução de exercícios em sala, com a ajuda dos tutores, até a resolução dos testes. É importante ressaltar que mesmo os desinteressados comentaram ser favoráveis à adoção da avaliação formativa.

De modo geral, em virtude do comprometimento da turma e de seu envolvimento no trabalho, esperavam-se ganhos estatisticamente significativos, o que não aconteceu. Dessa forma, não se pode afirmar que o emprego da avaliaçáo formativa associada à tutoria promova melhor desempenho dos alunos aos quais foi administrada. Como explicar esse fato? Embora o rendimento do grupo experimental tenha sido numericamente superior ao do grupo controle, não foi significativo.

Destacam-se pelo menos três fatores que podem ter influenciado o resultado da pesquisa. Um deles foi o tempo de duração do trabalho. Como foi desenvolvido no decorrer do terceiro bimestre e início do quarto, esse período (cerca de dois meses) foi pequeno. Os alunos demoraram algumas aulas para se organizarem para os testes e se habituarem a trabalhar em grupo, reduzindo, dessa maneira, o tempo destinado ao trabalho. Nas pesquisas em que houve diferença significativa no desempenho dos alunos, as intervençóes duraram cerca de um semestre; ressalta-se que essas pesquisas foram realizadas em turmas da educaçáo superior.

Uma segunda circunstância pode ter influído nos resultados: a proximidade do final do ano. Ocorre que, nessa época, os alunos, receosos de serem reprovados, dedicam-se mais aos estudos a partir do terceiro bimestre. Consequentemente, suas notas refletem o esforço extra feito por eles. Por fim, a terceira circunstância que pode ter reduzido a diferença de desempenho entre alunos dos grupos experimental e controle foi o suporte dado pelo professor nos plantóes de dúvidas, isto é, quando alunos dos dois grupos eram atendidos igualmente.

\section{Resultados quanto à satisfaçáo dos alunos}

Como mencionado anteriormente, esta pesquisa objetivou determinar a satisfação dos alunos com relação ao tipo de avaliação utilizado. A hipótese levantada foi a seguinte: inexiste diferença significativa em termos de satisfação dos alunos avaliados com base na avaliação somativa apenas e na satisfação dos alunos avaliados com base nas avaliaçóes somativa e formativa. 
Observando os resultados, concluiu-se que houve diferença significativa com relação à satisfação dos alunos, pois os valores de p encontrados foram inferiores a 0,05. Verificou-se, ainda, que essa diferença foi maior no grupo experimental, isto é, os alunos desse grupo se mostraram mais satisfeitos com o procedimento de avaliação utilizado do que os do outro grupo. Esse resultado também se confirmou em estudos anteriores, como os de Silva (1979) e Paredes (1984), feitos no âmbito do ensino médio. Notou-se que a avaliação formativa tornou o ambiente das aulas mais agradável e, consequentemente, mais propício à aprendizagem. De fato, as observaçóes da pesquisadora e os registros dos alunos confirmaram essa informação.

No início do trabalho, nas primeiras aulas, os alunos demonstraram estar um pouco confusos com a operacionalização do procedimento. Demoravam a formar os grupos e alguns deles relutavam em tirar suas dúvidas com os colegas. Mas a partir da quarta aula, ao final da primeira semana, tornaram-se mais ágeis na formação dos grupos, o que facilitava a organização da sala. Com isso, o tempo destinado à resolução de exercícios com a ajuda dos tutores foi melhor aproveitado. Observou-se que alguns alunos, particularmente os mais tímidos, sentiam-se mais à vontade para esclarecer as dúvidas com os colegas tutores.

Quando surgia alguma dúvida na resolução dos exercícios, os tutores recorriam ao professor, depois de discutirem possíveis alternativas de solução. Os alunos, ao se manifestarem sobre o trabalho, comentavam que estavam gostando muito, pois tinham a oportunidade de sanar suas dúvidas de forma particular, sem ter de se expor perante a turma inteira. Outros assinalaram que os tutores explicavam de forma mais acessível, detalhando melhor a resolução dos exercícios. Alguns deles disseram que "tinham menos vergonha de perguntar aos tutores do que ao professor".

O trabalho com a avaliação formativa também favoreceu a afetividade. Estando mais à vontade para resolver os exercícios, os alunos mostraram-se atenciosos e participativos, envolvendo-se com as tarefas propostas. Um aluno escreveu: "percebi a empolgação dos alunos por estarem aprendendo com os próprios colegas". Também demonstraram preocupação com os colegas que apresentavam dificuldade de aprendizado e enfatizaram que o trabalho propiciou uma "maior uniáo" da turma. Alguns ressaltaram o fato de o professor se preocupar com os alunos, se estavam aprendendo ou não, chegando a agradecer por isso.

Os discentes apontaram, ainda, que os erros passaram a ser encarados sem medo: "com esse trabalho a amizade fica melhor, assim a gente não tem medo de falar que está com dúvida". Os tutores assinalaram que o interesse, tanto deles quanto dos 
outros, pela matéria aumentou e, consequentemente, o ritmo de estudos. Em contrapartida, alguns observaram que, se os alunos fossem interessados o suficiente, não haveria necessidade de métodos diferentes, pois para uns não houve diferença no nível de interesse.

\section{CONCLUSÕES E CONSIDERAÇÕES FINAIS}

Como se procurou demonstrar, avaliar constitui-se em processo mais amplo do que simplesmente atribuir nota, aprovar ou reprovar. O processo de avaliar levanta questôes, tais como: o que se pretende com a avaliação? Quais os reflexos da avaliação sobre os indivíduos a ela submetidos? Por exemplo, a avaliação é o procedimento indicado quando se quer aperfeiçoar um material de instrução, selecionar alunos para um determinado curso por meio do vestibular, verificar se um método ou estratégia de ensino dá resultados positivos ou implantar uma política pública. Em todos esses casos, e em muitos outros, está-se fazendo avaliação. Entretanto, essa avaliação tem objetivos diferentes, logo cumprem funções diferentes.

De acordo com o presente estudo, não se pode afirmar que a avaliação formativa por meio da tutoria por alunos beneficie, de fato, a aprendizagem cognitiva, o que encontra respaldo em alguns estudos elencados na revisão da literatura. Ressalta-se, no entanto, que os resultados do pós-teste, em relação aos do pré-teste, foram numericamente superiores, mesmo náo tendo sido estatisticamente significativos. Apesar de náo se ter encontrado diferenças estatisticamente significativas no desempenho cognitivo dos alunos do grupo experimental em relação aos alunos do grupo controle, a satisfação dos alunos quanto ao procedimento adotado favoreceu, de forma significativa, o grupo experimental. Com isso, o ambiente de sala de aula tornou-se mais agradável e propício à aprendizagem, o que pode ser computado como fator positivo do uso da avaliação formativa.

A avaliação formativa permite ao professor detectar as falhas em sua prática, possibilitando o replanejamento constante das atividades escolares com base nas dificuldades apresentadas pelos alunos. Por outro lado, também possibilita aos alunos a detecção dos pontos que precisam ser melhorados. Os alunos, incluindo os tutores, citaram a vantagem de estar sabendo, antes das provas mensais e bimestrais, em que nível se encontravam com relação ao alcance dos objetivos. Além disso, a tutoria proporcionou a coesão entre os alunos, o que favoreceu o ambiente escolar. Os alunos tímidos, em particular, cuja conduta usual é a de evitar fazer perguntas durante a aula com medo de gracejos dos colegas, ressaltaram que se sentiam mais à vontade para tirar as dúvidas com os tutores. 
O resultado da tutoria, dentro e fora da sala de aula, foi tão bom que os alunos pedem constantemente a retomada do trabalho. Essa atividade superou de tal forma as expectativas que, possivelmente, será criado um projeto de tutoria para auxiliar os alunos com dificuldades, além do plantão de dúvidas já oferecido pela escola.

As perspectivas mais atuais da avaliação formativa a associam à avaliação mediadora (Hoffmann, 2005a), também conhecida por outras designaçôes já citadas. A avaliação mediadora propõe as práticas da individualização da aprendizagem e a diversificação de experiências educativas. Segundo Hoffmann (2005b) "mediação é aproximação, diálogo, acompanhamento do jeito de ser e de aprender de cada educando, dando-lhe a mão com rigor e afeto, para ajudá-lo a prosseguir sempre (...)”. Não seria a avaliação mediadora uma réplica da aprendizagem para o domínio?

Independentemente do nome que receba a avaliação, ressalta-se a importância que ela tem na aprendizagem do educando. $O$ professor deve ter a intenção de desenvolver estratégias pedagógicas desafiadoras com os alunos, baseado na observação e reflexão das manifestaçóes individuais de aprendizagem. Deve, ainda, dar mais atenção e dedicar um tempo maior a quem mais precisa, respeitando as diferenças e refletindo acerca de açóes educativas pertinentes aos interesses e necessidades do educando.

\section{REFERÊNCIAS BIBLIOGRÁFICAS}

ALLAL, L.; CARDINET, J.; PERRENOUD, P. A Avaliação formativa num ensino diferenciado. Tradução Clara Moura Lourenço; José Afonso Baptista. Coimbra: Livraria Almedina, 1986.

ALMEIDA, Alair Brandão. Efeitos de um modelo de avaliação formativa no processo de aprendizagem. 1976. Tese (Mestrado em Educação) - Faculdade de Educação, Universidade Federal do Rio Grande do Sul, Porto Alegre.

BLACK, P.; WILIAM, D. Assessment and classroom learning. Assessment in Education: Principles, Policy \& Practice, v. 5, n. 1, mar. 1998. Disponível em:<http://www.ped.gu.se/ personal/frank.bach/kurser/Black\&Wiliam. pdf>. Acesso em: 12 fev. 2006.

BLOOM, B. S. Human characteristics and school learning. New York: McGraw-Hill, 1976.

BLOOM, B. S. et al. Taxonomia de objetivos

educacionais: domínio cognitivo. Porto Alegre: Globo, 1972.

BRASIL. Ministério da Educação. Instituto Nacional de Estudos e Pesquisas Educacionais Anísio Teixeira. Qualidade da educação: uma nova leitura do desempenho dos estudantes da quarta série e da oitava série do ensino fundamental e da terceira série do ensino médio. 2004. Disponível em: <http://www. inep.gov.br>. Acesso em: 20 jul. 2005.

CAHEN, Leonard S.; ANDERSON, Scarvia B. Curriculum evaluation. In: ANDERSON, Scarvia B.; MURPHY, Richard T. (Org.). Encyclopedia of educational evaluation. San Francisco: JosseyBass Publishers, 1977.

DE VOLDER, M. L.; DE GRAVE, W. S.; GIJSELAERS, W. Peer teaching: academic achievement of teacher-led versus student-led discussion groups. Higher Education, v. 14, p. 643-650, 1985. 
DUTRA, A. H. Avaliação formativa: sua influência no rendimento escolar e no nível de satisfação dos alunos. 1977. Tese (Mestrado em Educação) - Faculdade de Educação, Universidade Federal do Rio Grande do Sul, Porto Alegre.

ESTEBAN, M. T. (Org.). Escola, currículo e avaliação. São Paulo: Cortez, 2003. (Cultura, memória e currículo, v. 5)

GOMES, S. Tessituras docentes de avaliação formativa. 2003. Tese (Mestrado em Educação) - Faculdade de Educação, Universidade Federal de Minas Gerais, Belo Horizonte.

HADJI, C. Avaliação desmistificada. Tradução Patrícia Chittoni Ramos. Porto Alegre: Artmed, 2001.

HOFFMANN, J. Avaliar para promover: as setas do caminho. 7.ed. Porto Alegre: Mediação, 2005a.

. O Jogo do contrário em avaliação.

Porto Alegre: Mediação, 2005b.

. Pontos e contrapontos: do pensar

ao agir em educação. 7.ed. Porto Alegre: Mediação, 2003.

KLAUSNER, I. Avaliação formativa e avaliação somativa na área de estudos sociais do curso de estudos adicionais. 1977. 401 f. Tese (Mestrado em Educação) - Universidade Federal Fluminense, Niterói.

LEWY, A. Formative and summative evaluation. In:WALBERG, Herbert J.; HAERTEL, Geneva D. The International encyclopedia of educational evaluation. Oxford: Pergamon Press, 1990.

PAREDES, M. A. T. Avaliação formativa: uma experiência com alunos do secundário. 1984. Tese (Mestrado em Educação) - Pontifícia Universidade Católica de São Paulo, São Paulo. PERRENOUD, Philippe. Avaliação da excelência à regulação das aprendizagens: entre suas lógicas. Tradução Patrícia Chittoni Ramos. Porto Alegre: Artmed, 1999. . Évaluation formative: cinquième roue du char ou cheval de Troie? Journal de l'Association pour lê développment de la mesure et de l'évaluation en éducation, v. 5, n. 4, p. 21-28, 1988.

RIBETTO, A. et al. Conversas sobre avaliação e comunicação. In: ESTEBAN, M. T. (Org.). Escola, currículo e avaliação. São Paulo: Cortez, 2003. p.101-118. (Cultura, memória e currículo, v. 5) ROBINSON, D. R.; SCHONFIELD, J. W.; STEERSWENTZELL, K. L. Peer and cross-age tutoring in Math: outcomes and their design implications. Educational Psychology Review, v. 17, n. 4, December 2005, p. 327-362.

RODRIGUES JUNIOR, J. F. A Taxonomia de objetivos educacionais: um manual para o usuário. Brasília: UnB, 1994.

SCRIVEN, M. The Methodology of evaluation. In: . Perspectives on curriculum evaluation. Chicago: Rand McNally and Co., 1967. (AERA Monograph Series on Curriculum Evaluation, n. 01)

SILVA, J. T. Avaliação formativa com suporte de aluno tutor: efeitos no rendimento classificado por nível cognitivo e na satisfação dos alunos. 2002. Tese (Mestrado em Educação) Faculdade de Educação, Universidade Católica de Brasília, Brasília-DF.

SILVA, M. C. Avaliação formativa e somativa: um estudo comparativo de seus efeitos no rendimento escolar, na retenção da aprendizagem e na atitude do aluno para com a disciplina. 1979. Tese (Mestrado em Educação) - Faculdade de Educação, Universidade Federal do Rio Grande do Sul, Porto Alegre-RS. VILLAS BOAS, B. M. de F. Avaliação é aprendizagem: como entender a avaliação formativa na formação de professores? In: ENCONTRO NACIONAL DE DIDÁTICA E PRÁTICA DE ENSINO - ENDIPE , 13, 2006, Recife. Anais... Recife: UFPE, 2006. - Portfólio, avaliação e trabalho pedagógico. 2.ed. Campinas: Papirus, 2004.

Recebido em: maio 2008

Aprovado para publicação em: dezembro 2008 
